\title{
$\underline{\text { A Descriptive Model of Managerial Effectiveness }}$
}

\author{
By: Fred Luthans, Dianne H. B. Welsh, and Lewis A. Taylor III
}

Luthans, F., Welsh, D.H.B., \& Taylor, L. (1988, June). A descriptive model of managerial effectiveness. Group \& Organization Studies, 13(2), 148-162.

\section{***Note: Figures may be missing from this format of the document}

\begin{abstract}
:
This study was designed to help understand what effective managers really do. Unlike previous research on managerial effectiveness, a diverse sample $(\mathrm{N}=78)$ of managers was directly observed in natural settings. These data on managerial activities gathered by trained observers were related to a subordinate-report measure of unit effectiveness. Using canonical correlation analysis, a descriptive model of managerial effectiveness was derived. This one-dimensional model consists of a continuum ranging from a quantity-oriented human resource manager (who was observed to exhibit considerable staffing and motivating or reinforcing activities and was perceived to have quantity performance in the unit) to quality- oriented traditional manager (who was observed to exhibit a lot of interaction with outsiders, controlling and planning activities, and was perceived to have quality performance in the unit). This empirically derived descriptive model helps identify needed managerial activities and skills for quantity and quality performance in today's organizations.

\section{Article:}

Effectiveness, whether it is organization- or manager-specific, is universally accepted as a major goal for modern management. Unfortunately, there is a lack of consensus and considerable disagreement on what is meant by effectiveness. How it is defined and measured largely depends on the theoretical orientation of the researcher. Organizational theorists and researchers have commonly used employee satisfaction, effort, or commitment (Cummings, 1980; Goodman \& Pennings, 1977) as the key to enhancing effectiveness, whereas those in policy look to strategic planning and structure interactions as a solution to increasing effectiveness (Rumelt, 1974). Also many with a financial perspective equate profit with effectiveness (Kirch off, 1977).

These traditional views primarily focus on the overall effectiveness of the organization. However, because of dynamic changes within organizations (for example, technological changes or a goal setting program), some organization theorists suggest that effectiveness should focus on the subunit level (Van de Ven \& Ferry, 1980). This is translated into better quality or more quantity of goods or services. This is especially true as today's organizations attempt to become more competitive in the global marketplace. It is this latter view of effectiveness, that is, quality and quantity of performance at the subunit level, that drives the present study of managerial effectiveness.
\end{abstract}

With few exceptions, traditional models of effectiveness in the organization and management literature have focused on conceptual variables such as structure and technology (Steers, 1975). A descriptive model that examines the relationship between effectiveness and day-to-day managerial activities has been ignored. The purpose of this study is to directly observe managers 
in their natural settings to determine their activities, and then relate these to effectiveness as defined as quality and quantity at the subunit level, in order to derive a descriptive model of managerial effectiveness.

\section{BACKGROUND FOR THE STUDY}

Although Thorndike (1949) was the first to make note of the trend to measure effectiveness by defining the statement of some ultimate criterion, Campbell (1974) identified nineteen different variables used to measure effectiveness. The most commonly used univariate measures include: (a) overall performance (measured by employee or supervisory ratings); (b) productivity (actual output data); (c) employee satisfaction (self-report questionnaires); (d) profit (accounting data); and (e) withdrawal (turnover or absenteeism data). However, Steers (1975) points out that such univariate measures may be limited in the analysis of effectiveness because they are noncomprehensive, lack objectivity, and fail to integrate.

Because multivariate models are more comprehensive and can account for a greater proportion of the variance in effectiveness, they are generally looked upon as superior. Georgopoulos and Tannenbaum (1957) were the first to use a multivariate model of effectiveness, and since their study multivariate models have proliferated. Steers (1975) summarized 17 representative models and found little overlap across the various approaches. Adaptability- flexibility was the criterion mentioned most often, whereas productivity followed close behind. A Scale of Organizational Effectiveness developed by Mott (1972) defined effectiveness along these lines - adaptability, flexibility, and productivity. This study uses the Mott questionnaire.

The lack of concurrence of evaluation criteria in traditional models of effectiveness points to the complexity of the construct and the problem in simplifying it into definitive criteria. Steers (1975) suggests that more flexible, comprehensive models are in order; models that integrate macro- and microvariables of effectiveness. In order to develop a descriptive model of managerial effectiveness, especially one that has implications for practicing managers, there seems a need to examine the relationships between specific, directly observable managerial activities and organizational effectiveness dimensions. This study attempts to meet this need.

Besides meeting the need for a more flexible, comprehensive model for managerial effectiveness, the study also was designed to build on the descriptive observational work of Mintzberg (1975) and Kotter (1982). Based on behavioral observations of five chief executives, Mintzberg was critical of the "folklore" (1975) of the traditional managerial activities. Based on observational data, he formulated a typology of managerial behavior based on three interpersonal roles (figurehead, leader, and liaison), three informational roles (monitor, disseminator, and spokesman), and four decision-making roles (entrepreneur, disturbance handler, resource allocator, and negotiator). Although he makes some generalized statements about the relative importance of these with different levels and types of management, and although there have been several studies that have attempted to verify the categories (Alexander, 1979; Kurke \& Aldrich, 1983; Lau, Newman, \& Broedling, 1980; McCall \& Segrist, 1980; Snyder \& Wheelen, 1981), no research to date has related observed managerial activities from the Mintz- berg typology with managerial effectiveness. 
Kotter (1982) used some observational data to study 15 successful general managers from a variety of industries. Like Mintzberg, he also found them to behave quite differently from the traditional model. In particular, he found these managers to spend considerable time and effort building informal networks. He then drew conclusions that the quality of the general managers' networking influences their performance through the contribution to and implementation of what he calls their "agendas." These conclusions were not derived through statistical or even systematic qualitative analysis, but rather were the results of Kotter's overall impressions.

The present study comes out of a stream of research on what are called Real Managers (Luthans, Hodgetts, \& Rosenkrantz, 1988). Earlier studies have analyzed successful managers (Luthans, Rosenkrantz, \& Hennessey, 1985), managerial communication (Luthans \& Larsen, 1986), and the difference between successful and effective managers (Luthans, in press). This study focuses on deriving a descriptive model of managerial effectiveness.

\section{METHODOLOGY}

\section{SAMPLE AND MEASURES}

To analyze the relationship between directly observed managerial activities and organizational subunit effectiveness, a diverse sample of 78 managers was used. These managers came from all levels and all types of large and small organizations including manufacturing, retail, financial, transportation, and public sector organizations. This sample was one wave of data collection in a large 4-year study (see Luthans et al., 1988, for more details). Because only one manager was observed in some organizations and several in others, there were many different organizations represented. In all cases, the managers had subordinates working directly for them.

The frequency of activities of these 78 target managers was recorded by trained observers on a one-page observation system developed by Luthans and Lockwood (1984). The observer training consisted of a half-day workshop devoted to going over the observation approach in general and the managerial activity categories in particular. The observers were given careful instruction on potential observation errors (following Thorton \& Zorich, 1980) and how to overcome them. This training also included demonstration and practice using role-playing skits that illustrated the various observable behaviors representing the managerial activities.

Table 1 shows the categories of managerial activities and their behavioral descriptors. For example, the activity of "monitoring/controlling performance" has directly observable behavioral descrip-

\section{TABLE 1}

Observation Categories of Managerial Activities

with Behavioral Descriptors 
Planning/coordinating

setting goals and objectives

defining tasks needed to accomplish goals

scheduling employees, timetables

assigning tasks and providing routine instructions

coordinating activities of each subordinate to keep work running smoothly

organizing the work

\section{Staffing}

developing job descriptions for position openings

reviewing applications

interviewing applicants

hiring

contacting applicants to inform them of being hired or not

"filling in" where needed

Training/developing

orienting employees, arranging for training seminars, and so on

clarifying roles, duties, job descriptions

coaching, mentoring, walking subordinates through task

helping subordinates with personal development plans

Processing paperwork

processing mail

reading reports, in-box

writing reports, memos, letters, and so on

routine financial reporting and bookkeeping

general desk work

Monitoring/controlling performance

inspecting work

walking around and checking things out, touring

monitoring performance data (e.g., computer printouts, production, financial reports)

preventive maintenance

Motivating/reinforcing

allocating formal organizational rewards

asking for input, participation

conveying appreciation, compliments

giving credit where due

listening to suggestions

giving position performance feedback

increasing job challenge

delegating responsibility and authority

letting subordinates determine how to do their own work

sticking up for the group to superiors and others, backing a subordinate

TABLE 1 Continued

Interacting with outsiders

public relations

customers

contacts with suppliers, vendors

external meetings

community-service activities

Managing conflict

managing interpersonal conflict between subordinate or others

appealing to higher authority to resolve a dispute

appealing to third-party negotiators

trying to get cooperation or consensus between conflicting parties

attempting to resolve conflicts between subordinate and self

Socializing/politicking

nonwork-related chit chat (e.g., family or personal matters)

informal "joking around," B.S.

discussing rumors, hearsay, grapevine

complaining, griping, putting others down

politicking, gamesmanship

NOTE: Adapted from Luthans and Lockwood (1984). 
tors of inspecting work, walking around and checking things out, touring, monitoring performance data (e.g., computer printouts, production and financial reports), and doing preventive maintenance.

The development of the categories and the reliability and validity analysis of this observation system can be found in Luthans and Lockwood (1984). A checklist based on the observation system was filled out by the trained observers (graduate students who were or became familiar with the functions, terminology, and nature of the target manager's job) once every hour (at a randomly designated time) for a 2 -week period (a total of 80 observation periods).

Interrater reliability was determined by agreement between the trained observer and a roving outside observer (a member of the research team). This outside observer would show up at random times and fill out the observation sheet at the same time, and then the percentage of agreement would be checked. For this sample, the observers met the $90 \%$ agreement criterion. On earlier samples using the same observation system and procedures (Luthans \& Lockwood, 1984), Cohen's (1960) kappa statistic, which specifically represents the proportion of joint judgments on which there is agreement, after chance agreement is excluded, was calculated to be a highly significant $(\mathrm{p}<.001) .81$.

Organizational subunit effectiveness was measured by Mott's (1972) Organizational Effectiveness Questionnaire. He defined organizational effectiveness as "the ability of an organization to mobilize its centers of power for action-production and adaptation" (p. 17). Subordinates of the target managers confidentially reported their perception of the effectiveness of their unit. In all cases, there was a minimum of two subordinates per target manager. If the manager had a large number of subordinates, the questionnaire was administered to a random sample of them. In total, 287 subordinates (an average of about 4 subordinates per manager) filled out the effectiveness questionnaire. Importantly, these were not the observers; so there is no same-source bias problem in this study. Subordinates were used to provide the perceived effectiveness data because they were deemed to have the most comprehensive and unbiased view of performance of the target manager's unit.

The Mott questionnaire has three subscales (productivity, adaptability, and flexibility) and a summative overall effectiveness scale. The productivity measure is further broken down into quantity and quality of the product or service as well as the efficiency with which it is produced or delivered. Adaptability includes both symbolic adaptation and behavioral adaptation. Mott (1972) defines symbolic adaptation as both anticipating problems in advance and developing satisfactory and timely solutions to them in addition to staying abreast of new technologies and methods applicable to the activities of the organization. Behavioral adaptation is defined as prompt and prevalent acceptance of solutions. The psychometric properties of the scales were quite good when Mott developed the scale, and it has been used by organizational behavior researchers with further psychometric support (Schriesheim \& Fulk, 1981). The Cronbach alphas for the present sample were .69 for the productivity scale, .69 for the adaptability scale, and .79 for the overall effectiveness scale (flexibility was a one-item scale). 
Because the measures of both managerial activities and subunit effectiveness were multivariate, a canonical correlation analysis was used. Relationships between sets of multiple criterion variables are analyzed with canonical correlation (Darlington, Weinberg, \& Walberg, 1973; Hair, Anderson, Tatham, \& Grablowsky, 1979; Levine, 1977; Tucker \& Chase, 1980). In this particular study, the data on the nine categories of managerial activities and the eight questions on organizational subunit effectiveness were canonically correlated to determine if any significant relationships existed $(\mathrm{p}<.05)$.

The purpose of using canonical correlation analysis in this study is to describe the nature of the relationships between two sets of variables. The underlying logic of the canonical correlation interpretation used in this study was stated by Hair et al. (1979) as involving "the derivation of a linear combination of variables from each of the two sets of variables so that the correlation between the two linear combinations is maximized" (p.182). The two sets of variables in the canonical analysis of this study are the frequencies of the directly observed managerial activities and the scores on the organizational subunit effectiveness questionnaires filled out by subordinates. Importantly, the results of the canonical analysis do not permit causal conclusions, but instead help describe the relationship between managerial activities and effectiveness.

\section{RESULTS}

The relative frequencies of the activities of the target managers recorded by the trained observers in the natural setting are shown in Table 2. Approximately one-fourth of the directly observed managerial activity was categorized as planning/coordinating. Processing paperwork was the next most frequently observed activity (19\%), followed by interacting with outsiders (13\%), and monitoring/controlling performance (11\%). The remaining activities were all less than $10 \%$. Thus over a third of the managerial activity was observed to be traditional functions of planning and control. Human resource management activities such as training and developing, staffing, managing conflict, and motivating/reinforcing were all individually less than $10 \%$, but aggregated represented almost one-fourth of the activities of these managers.

Table 3 shows the means and standard deviations for the various subscales on the Mott (1972) organizational subunit effectiveness questionnaire. These results represent the subordinates' perceptions of their organizational subunit effectiveness.

TABLE 2

Directly Observed Activities of Managers $(\mathrm{N}=78)$ in the Natural Setting ${ }^{\mathrm{a}}$

\begin{tabular}{lc} 
Relative & Percentage \\
\hline Planning/coordinating & 23 \\
Processing paperwork & 19 \\
Interacting with outsiders & 13 \\
Monitoring/controlling performance & 11 \\
Socializing/politicking & 9 \\
Training/developing & 8 \\
Staffing & 5 \\
Managing conflict & 5 \\
Motivating/reinforcing & 4 \\
\hline
\end{tabular}

a. See Table 1 for the behavioral descriptions of these activities.

b. Numbers do not add up to one hundred because of rounding. 
The canonical correlation analysis reveals the nature and extent of the relationships between the subordinate-reported organizational subunit effectiveness measures and the directly observed managerial activities. There was one highly significant canonical variate. As shown in Table 4, the canonical correlation $(\mathrm{Rc}=.4402, \mathrm{p}<.01)$ contains several relationships between the subordinate- reported effectiveness measures and the observed managerial activities.

Of the nine managerial activities, five were strongly correlated with the variate. As seen in Table 4, staffing had a strong positive relationship to this variate and motivating/reinforcing also positively correlated but to a slightly lesser degree. On the other hand, interacting with outsiders and monitoring/controlling performance have strong negative relationships, and planning/coordinating was also negatively correlated but to a slightly lesser degree.

Three of the effectiveness measures were strongly correlated with the variate. Table 4 shows that productivity-quantity and productivity-efficiency had a strong positive relationship in this variate. Productivity-quality, on the other hand, had a strong negative relationship.

In summary, the relationships between the subordinate-reported organizational subunit effectiveness measures and the directly observed managerial activities for the variate could be conceptually

TABLE 3

Subordinate-Reported Organizational Effectiveness Mott (1972) Scales $(\mathrm{N}=287)$

\begin{tabular}{lcc}
$\begin{array}{l}\text { Subscales of } \\
\text { Organizational Effectiveness }\end{array}$ & Means & $\begin{array}{c}\text { Standard } \\
\text { Deviations }\end{array}$ \\
\hline Flexibility & 4.17 & 0.82 \\
Productivity-quality & 4.11 & 0.70 \\
Productivity-quantity & 3.94 & 0.78 \\
Adaptation-prevalence of adjustment & 3.82 & 1.11 \\
Adaptation-solutions & 3.73 & 0.87 \\
Adaptation-promptness of adjustment & 3.73 & 0.96 \\
Adaptation-anticipation & 3.59 & 0.82 \\
Productivity-efficiency & 3.57 & 0.76 \\
\hline
\end{tabular}

described on a continuum going from quantity-oriented human resources manager to qualityoriented traditional manager. More specifically, effective managers could be described to range from quantity- and efficiency-oriented and exhibiting more human resource management activities such as staffing and motivating/reinforcing to quality-oriented and engaging in a lot of interaction with outsiders and exhibiting more traditional management activities such as planning and control. Figure 1 presents this model using the data from Table 4 to place the results along a continuum. Or highly simplified, the one-dimensional descriptive model of managerial effectiveness could be presented as:

$\begin{array}{ll}\text { Quality-Oriented ___ Quantity-Oriented } & \\ \text { Traditional Manager } & \text { Human Resources Manager }\end{array}$

\section{DISCUSSION}


The results of this study provide the beginnings of a descriptive model of managerial effectiveness. Unlike previous studies on managerial effectiveness, this study used multiple measures from different sources, both a subordinate-reported questionnaire and direct observation of managerial activities. According to the findings in this study, observed activities of managers in the natural setting do relate differentially to organizational subunit effectiveness as defined by the Mott scales (1972).

In particular, the productivity scale separated into a quantity and quality orientation by distinctly different activities of the managers

TABLE 4

Canonical Correlation Coefficients Between the Canonical Variate and Effectiveness Measures and Managerial Activities

\begin{tabular}{lc} 
& \begin{tabular}{c} 
Structural $^{\text {Coefficients }}{ }^{\mathrm{a}}$ \\
\hline Effectiveness measures
\end{tabular} \\
Productivity-quantity & .7651 \\
Productivity-quality & -.7882 \\
Productivity-efficiency & .5043 \\
Adaptation-anticipation & .1768 \\
Adaptation-solutions & .0397 \\
Adaptation-promptness of adjustment & .0198 \\
Adaptation-prevalence of adjustment & -.0678 \\
Flexibility & .0232 \\
Managerial activities & \\
Monitoring/controlling performance & -.4222 \\
Interacting with outsiders & -.4766 \\
Managing conflict & .1998 \\
Motivating/reinforcing & .3688 \\
Planning/coordinating & -.3135 \\
Processing paperwork & .0638 \\
Socializing/politicking & -.1099 \\
Staffing & .5329 \\
Training/developing & -.2826 \\
Canonical correlation & .4402 \\
Canonical R-squared & .1938 \\
Degrees of freedom & $72 ; 1607.3$ \\
F statistic & $1.7713^{*}$ \\
\hline fined as the correlations between the variates and the individual variables composing the variate. & \\
& $* .0001$.
\end{tabular}

observed. Although the results suggest that managers who run quality-oriented units do a lot of interaction with external others (for example, suppliers or consultants), the results also show they do a lot of the traditional activities such as monitoring/controlling performance and planning/coordinating. This finding is in direct contrast to Mintzberg's (1975) observational study, which found that top-level managers spent little time in performing traditional functions, such as planning.

The findings of the earlier study on successful managers (Luthans et al., 1985) found that most successful (defined as those promoted relatively fast) managers perform significantly fewer activities 


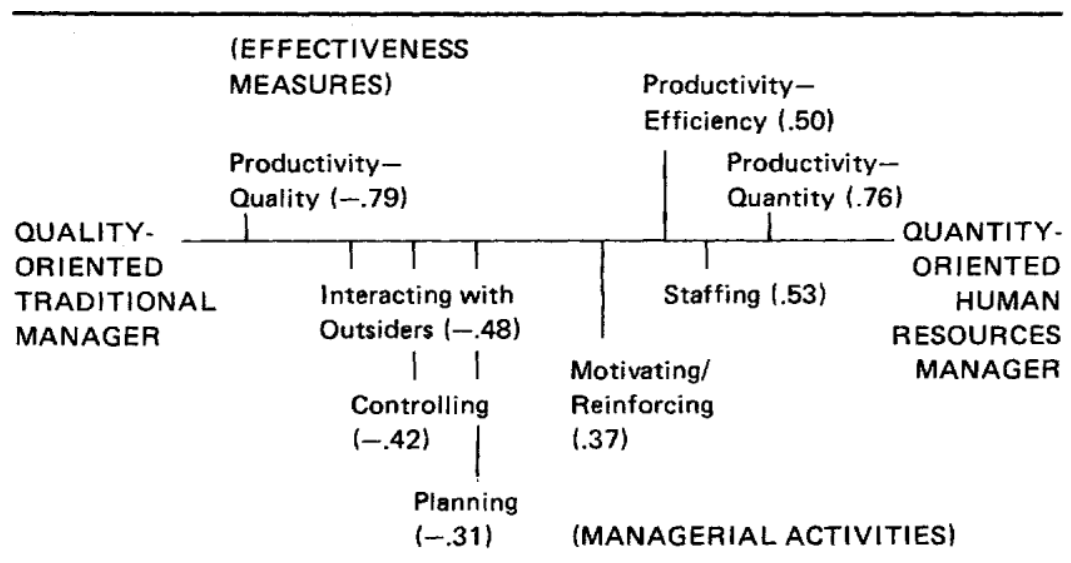

Figure 1: Descriptive Model of Managerial Effectiveness.

classified as the traditional activities. Specifically, four of the five activities in the present study related to effective managers are indicative of unsuccessful managers (those promoted relatively slowly) in the earlier study---planning, controlling, motivating/reinforcing, and staffing.

Importantly, these findings suggest that activities that relate to effective managers (in this study human resource management activities for quantity-oriented effective managers and traditional activities for quality-oriented effective managers) are not necessarily the same as those that relate to successful managers. This important distinction between successful and effective managers and its implications for the performance of today's organizations is fully discussed in Luthans (in press).

The other two dimensions of productivity on the Mott scale (1972), quantity and efficiency, also had some positive relationships with the observed managerial activities. These managers, seen by subordinates as running quantity-oriented effective subunits, were observed doing a considerable amount of the staffing activity and, to a slightly lesser degree, the motivating/reinforcing activity. These human resource management activities were observed occurring least among successful managers (those on a fast promotion track) in the earlier study (Luthans et al., 1985). Thus once again, the activities of the successful managers determined in the earlier study may be quite different from the effective managers of the present study.

\section{CONCLUSIONS AND IMPLICATIONS}

Managerial effectiveness is generally regarded as one of the most sought-after, but elusively defined and measured concepts in group and organization studies. Numerous studies have investigated it over the years. However, the question of what specific activities of practicing managers relate to effectiveness had not been answered. This study investigated the question by conducting a canonical correlation analysis of two sets of data gathered via subordinate- reported subunit organizational effectiveness measures and the directly observed day-to-day activities of practicing managers in the natural setting. The results of this analysis are expressed in the onedimensional managerial effectiveness model shown in Figure 1.

The nature of the relationship between subunit effectiveness measures and the observed managerial activities in the significant canonical variate suggests a quantity-oriented human resource manager and quality-oriented traditional manager conceptual continuum. The quantity- 
oriented human resource manager describes effective managers who are observed to exhibit considerable staffing and motivating/reinforcing activities and are perceived to have quantity performance in their units. They exhibit much less interacting with outsiders, controlling and planning activities, and are not perceived to have quality performance in their units. The qualityoriented traditional manager depicts the mirror opposite. In particular, these managers exhibit considerable interacting with outsiders, controlling and planning activities, and are perceived to have quality performance in their units. By the same token, they exhibit hardly any human resource management activities and are not perceived to have quantity performance in their units.

This study is a departure from the previous research on managerial effectiveness. Due to the multiple methods and the strong relationships evident in the correlations in this study, considerable confidence can be given to the results. Nevertheless, there are some obvious limitations, and further research is in order. For example, neither the effects of managerial level nor type of organization were investigated. Most important for the future, however, would be to test the derived descriptive model. Knowledge would then be furthered from simply describing what activities effective managers do to noting what managers should do to be the most effective. This would help close the gap between researcher's knowledge and practitioners' behavior and performance.

The study as it stands, however, does describe some important relationships between day-to-day managerial activities and effectiveness. This should help organization development specialists identify activities and skills needed for quality or quantity performance in today's organizations. For example, the model would suggest that human resource management activities (such as staffing and motivating/reinforcing) may help attain more output (quantity of performance), but more traditional management activities (such as planning, controlling, and keeping in contact with outsiders such as suppliers) may help improve quality performance.

\section{REFERENCES}

Alexander, L. D. (1979). The effect level in the hierarchy and functional area have on the extent Mintzberg's roles are required by managerial jobs. Proceedings of the Academy of Management.

Campbell, J. P. (1974). The measurement of organizational effectiveness: A review of relevant research and opinion. Minneapolis: Personnel Decisions.

Cohen, J. (1960). A coefficient of agreement for nominal scales. Educational and Psychological Measurement, 20, 37-46.

Cummings, L. L. (1980). Productivity challenge: A behavioral perspective. Proceedings of the Academy of Inter-disciplinary Sciences. Las Vegas.

Darlington, R. B., Weinberg, S. L., \& Walberg, H. J. (1973). Canonical variate analysis and related techniques. Review of Educational Research, 43, 433-454.

Georgopoulos, B. S., \& Tannenbaum, A. S. (1957). The study of organizational effectiveness. American Sociological Review, 22, 534-540. 
Goodman, P. S., \& Penn ings, J. M. (1977). New perspectives on organizational effectiveness. San Francisco: Jossey-Bass.

Hair, J. F., Anderson, R. E., Tatham, R. L., \& Grablowsky, B. J. (1979). Multivariate data analysis. Tulsa, OK: Petroleum Publishing.

Kirchoff, B. (1977). Organizational effectiveness measurement and policy research. Academy of Management Review, 1, 347-355.

Kotter, J. P. (1982). The general managers. New York: Free Press.

Kurke, L. B., \& Aldrich, H. E. (1983). Mintzberg was right! A replication and extension of the nature of managerial work. Management Science, 29, 975-984.

Lau, A. W., Newman, A. R., \& Broedling, L. A. (1980). The nature of managerial work in the public sector. Public Management Forum, 19, 513-521.

Levine, M. S. (1977). Canonical analysis and factor comparison. Beverly Hills, CA: Sage.

Luthans, F. (in press). Successful versus effective real managers. Academy of Management Executive.

Luthans, F., Hodgetts, R. M., \& Rosen krantz, S. A. (1988). Real managers. Cambridge, MA: Ballinger.

Luthans, F., \& Larsen, J. K. (1986). How managers really communicate. Human Relations, 39, 161-178.

Luthans, F., \& Lockwood, D. L. (1984). Toward an observation system for measuring leader behavior in natural settings. In J. G. Hunt, D. Hosking, C. Schriesheim, \& R. Stewart (Eds.), Leaders and managers: International perspectives on managerial behavior and leadership (pp. 117-141). New York: Pergamon Press.

Luthans, F., Rosenkrantz, S. A., \& Hennessey, H. (1985). What do successful managers really do? Journal of Applied Behavioral Science, 21, 255-270.

McCall, M. W., \& Segrist, C. A. (1980). In pursuit of the manager's job: Building on Mintzberg. Greensboro, NC: Center for Creative Leadership.

Mintzberg, H. (1975). The manager's job: Folklore and fact. Harvard Business Review, 53(4), 49-61.

Mott, P. E. (1972). The characteristics of effective organizations. New York: Harper \& Row.

Rumelt, R. P. (1974). Strategy, structure and economic performance. Boston: Graduate School of Business, Harvard University. 
Schriesheim, C. A., \& Fulk, J. L. (1981). Subordinate self-perceptions of performance as a moderator of the effects of directive leadership: A path-goal theory extension. Proceedings of the Academy of Management.

Snyder, H. H., \& Wheelen, T. L. (1981). Managerial roles: Mintzberg and the management process theorists. Proceedings of the Academy of Management.

Steers, R. M. (1975). Problems in the measurement of organizational-effectiveness. Administrative Science Quarterly, 20, 546-558.

Thorndike, R. L. (1949). Personnel selection: Test and measurement techniques. New York: John Wiley.

Thorton, G. E., III, \& Zorich, S. (1980). Training to improve observer accuracy. Journal of Applied Psychology, 65, 351-354.

Tucker, R. K., \& Chase, L. J. (1980). Canonical correlation. In P. R. Monge \& J. N. Cappella (Eds.), Multivariate techniques in human communication research. New York: Academic Press.

Van de Ven, A., \& Ferry, D. L. (1980). Measuring and assessing organizations. New York: John Wiley.

Fred Luthans is George Holmes Distinguished Professor of Management at the University of Nebraska and is past president of the Academy of Management. A past contributor to Group \& Organization Studies, he has published numerous books and articles in organizational behavior and development.

Dianne H. B. Welsh is currently an Assistant Professor of Management at Eastern Washington University. She is doing research on the impact of behavioral principles on the performance of part-time employees in the service sector.

Lewis A. Taylor III is Assistant Professor of Management at the University of Miami. A past contributor to Group \& Organization Studies, and a number of other journals, his current research primarily involves behavioral decision making and its implications for administrative policy. 